\title{
Mapping the liquefaction potential index (LPI) in Ratu Agung subdistrict, Bengkulu City, Indonesia using the shear wave velocity approach
}

\author{
Ceri Eliesa Suhartini ${ }^{1}$, Lindung Zalbuin Mase $^{2}$, and Muhammad Farid ${ }^{3 *}$ \\ ${ }^{1}$ Department of Geological Engineering, Faculty of Engineering, University of Gadjah Mada, Indonesia; \\ ${ }^{2}$ Department of Civil Engineering, Faculty of Engineering, University of Bengkulu, Indonesia; \\ ${ }^{3}$ Department of Physics, Faculty of Mathematics and Natural Sciences, University of Bengkulu, Indonesia;
}

\begin{abstract}
On the $4^{\text {th }}$ of June, 2000 and $12^{\text {th }}$ of September, 2007, Ratu Agung Sub-district, Indonesia experienced significant damage due to liquefaction after the earthquakes. Therefore, this study aims to determine the Liquefaction Potential Index in the area. Data of shear wave velocity $\left(\mathrm{V}_{\mathrm{s}}\right)$ was collected using the Multichannel Analysis of Surface Wave (MASW) method. The measurement location was set up on a grid of 32 observations points with field investigations. Furthermore, Simplified Procedure and LPI methods were used to measure the soil liquefaction potential and vulnerability level. The results showed that the value of shear wave velocity in the Ratu Agung Subdistrict ranged from $102 \mathrm{~m} / \mathrm{s}$ to $442 \mathrm{~m} / \mathrm{s}$. Also, the liquefaction vulnerability levels varied from high to very high categories due to the maximum soil acceleration and conditions dominated by loose sand, as well as the influence of different geological formations in the zone. In conclusion, an empirical equation was successfully proposed to analyze the liquefaction vulnerability.
\end{abstract}

\section{Introduction}

Bengkulu City is vulnerable to earthquakes that trigger liquefaction [1], due to the Indo-Australian and the Eurasian Plates subduction zone. Meanwhile, the interaction movement between these plates affects the formation of the fault in the western part of Sumatra including faults of Mentawai and Semangko [2]. Geologically, Bengkulu City is dominated by alluvial materials consisting of sand, clay, and mud [3] which are potentially to undergo liquefaction $[4,5]$. The trigger factor of liquefaction in Bengkulu City is the earthquake event that occurred on June 4, 2000, and September 12, 2007, with magnitudes of $\mathrm{M}_{\mathrm{w}} 8.0$ and $\mathrm{M}_{\mathrm{w}} 8.6$, respectively. Those earthquakes are later known as Bengkulu-Enggano Earthquake and Bengkulu-Mentawai Earthquake, respectively. The earthquake had triggered liquefaction that was marked by soil subsidence and structural damage as shown in Fig. 1. Several previous studies also showed that the coastal zone of Bengkulu City including Ratu Agung Sub-district is vulnerable to undergo liquefaction as well [6].

The liquefaction potential map was composed based on LPI criteria. The investigation method used by a cone penetration test, whereas the investigations using other methods, such as standard penetration test and geophysical measurement are still limited. The results showed that the soil layer in the zone of the coastal area is liquefied [7]. Therefore, it is necessary to conduct further studies on liquefaction potential and its vulnerability level in this area. Several liquefaction events had been found in Ratu Agung District.

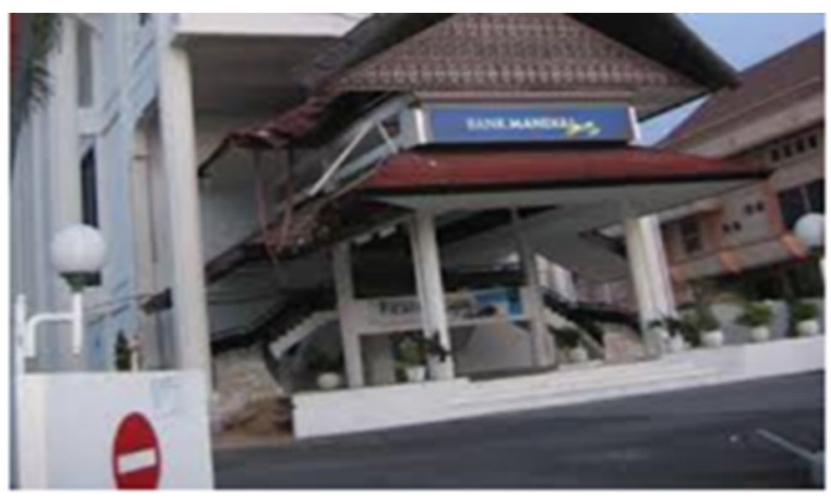

Fig. 1. Damage due to Liquefaction in Bengkulu City after the 2007 Earthquake [8]

As an area that is identified as the most impacted area during the earthquake in 2007, the Ratu Agung area becomes an interesting study area for the local study of earthquake engineering in Bengkulu City. This paper presents the mapping of the liquefaction vulnerability of the Ratu Agung District. This study used the data from the shear wave velocity $\left(V_{s}\right)$ data from geophysical

\footnotetext{
*Corresponding Author: $\underline{\text { mfarid@unib.ac.id }}$
} 
measurement, i.e. Multichannel Analysis of Surface Wave (MASW) method. $V_{s}$ data is then used to analyze the soil liquefaction vulnerability in the Ratu Agung Subdistrict. This study employed the method proposed to help for determining the liquefaction potential [9]. To quantify the liquefaction potential index in the study area, the weighted method called liquefaction potential index (LPI) is also used [10]. In general, this study could help a better understanding for local people to consider liquefaction impact in the study area.

\section{Theoretical Background}

\subsection{Liquefaction}

Liquefaction is the condition where the soil layer undergoes the loss of soil strength due to excess pore water stress arising under cyclical loading [11]. Generally, liquefaction occurs on loose sandy soils under saturated conditions. Once this soil type is receiving cyclic load, the contact between each particle suddenly disappears and the soil behaves like a liquid. It means that the bearing capacity of soil also disappears during the earthquake shaking and excess pore water pressure. The increase of pore water pressure is generally accompanied by changes in soil volume which are manifested as ground settlements, lateral spreads, and sand boils [12].

Several areas including Banda Aceh, Padang, Bengkulu, and Yogyakarta experienced sand boils, lateral spreads, as well as ground fractures, during the earthquake events that occurred in these areas. Those cause damage to buildings and grounds after earthquakes. The liquefaction phenomenon is generally found on alluvial plains, delta and swamp deposits, and brackish, as well as coastal embankments [13]. The contribution of an active fault called the Opak Fault had resulted in the earthquake and liquefaction in the Yogyakarta region. In line with those previous studies, therefore it is important to identify liquefaction in an area $[14,15]$.

\subsection{Shear Wave Velocity}

Shear wave velocity or $V_{s}$ is an important parameter that can be used for various geotechnical purposes, especially for engineering practice on the aspect of soil dynamics and earthquake engineering [16]. $V_{s}$ is determined from geophysical measurements, such as MASW. Soft soil has generally a lower $V_{s}$ because it is not compacted. Therefore, the shear wave propagation tends to be an easy passing soft layer. For liquefaction investigation, $V_{s}$ values are also used. Engineers tend to select this parameter for liquefaction investigation because the method is cheap, easy, and simple.

Before analyzing liquefaction, the corrected $V_{s}$ should be firstly determined [17]. Equation 1 shows correlation for corrected $V_{s}$,

$$
V_{s 1}=V_{s}\left(\frac{P_{a}}{\sigma_{v}^{\prime}}\right)^{0.25}
$$

In Equation 1, it can be seen that $V_{s I}$ is corrected $V_{s}$ in the unit of $\mathrm{m} / \mathrm{s}, \mathrm{P}_{\mathrm{a}}$ is as atmospheric pressure (i.e $100 \mathrm{kPa}$ ), and $\sigma_{v}$ 'is the vertical effective stress in $\mathrm{kPa}$.

As elaborated in the previous section, the benefit of $V_{s}$ is also able to use for soil type prediction and unit weight estimation [16]. These parameters are going to be used as the main parameter to estimate liquefaction potential [18],

$$
\gamma_{\text {sat }}=8.32 \log V_{s}-1.61 \log (z)
$$

In Equation 2, it shows that saturated unit weight is defined as $\gamma_{\text {sat }}\left(\mathrm{kN} / \mathrm{m}^{3}\right)$ and $z$ is the analyzed depth. $V_{s}$ and $\gamma_{\text {sat }}$ can use to predict soil type as shown by the chart presented in Fig. 2 indicate that saturated unit weight together with $V_{s}$ value can be used to estimate soil type. This framework is used in this study.

\subsection{Liquefaction Potential Analysis}

A simple procedure method was used to analyze the liquefaction by comparing Cyclic Stress Ratio (CSR) to Cyclic Resistance Ratio (CRR) [9]. Parameters called CSR and $C R R$ reflect the cyclic ratio of earthquake loading and the availability of soil resistance during the earthquake loading, respectively. $C S R$ is estimated by using the following equation,

$$
C S R=0.65 r_{d}\left(\frac{a_{\max }}{g}\right)\left(\frac{\sigma_{v}}{\sigma_{v^{\prime}}}\right)\left(\frac{1}{K_{\sigma}}\right)
$$

In Equation 3, $a_{\max }$ is defined as maximum ground surface acceleration resulting during the earthquake. Both parameters, i.e $\sigma_{v}$ and $\sigma_{v}{ }^{\prime}$ are total and effective stresses at the investigated depth, and $K_{\sigma}$ is the corrected overburden pressure factor, and $r_{d}$ is the depth reduction factor. For $r_{d}$ and $\mathrm{K}_{\sigma}$ parameters are estimated below,

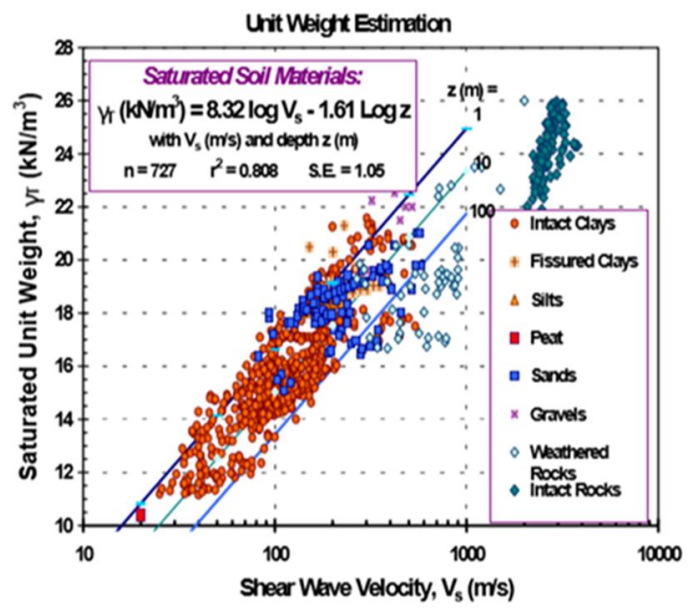

Fig. 2. The correlation between $\gamma_{\text {sat }}$ against $v_{s}$ [11]

$$
\begin{aligned}
& r_{d}=1-0.012 z \\
& K_{\sigma}=1-C_{\sigma} \ln \left(\frac{\sigma_{v}^{\prime}}{P_{a}}\right) \leq 1.1 \\
& C_{\sigma}=\frac{1}{18.9-2.55 \sqrt{\left(N_{1}\right)_{60}}} \leq 0.3
\end{aligned}
$$




$$
\left(N_{1}\right)_{60}=\left(\frac{V_{s 1}}{93.2}\right)^{\frac{1}{0.231}}
$$

From those equations, $z$ is defined as analyzed depth (in m length), $C_{\sigma}$ is the overburden pressure coeficient (dimensionless factor), and $\left(N_{I}\right)_{60}$ is the corrected standard penetration test (blows/ft).

$C R R$ is estimated by using Equation 8. In this study, $C R R$ is estimated based on $V_{s}$ data. In Equation 8, several parameters called Magnitude Scaling Factor $(M S F)$ [19] and factors for $V_{s}$ correction $\left(K_{a 1}\right.$ and $\left.K_{a 2}\right)[20,21]$ are introduced. For $K_{a 1}$ and $K_{a 2}$, the detailed explanation of how to estimate those factors are presented in Andrus et $a l$. [20, 21]. $M S F$ factor is related to the magnitude of the earthquake $\left(M_{w}\right)$. For MSF, the calculation procedure is expressed in Equation 9,

$$
\begin{aligned}
& C R R=M S F\left(\begin{array}{l}
0.022\left(\frac{K_{a 1} V_{s 1}}{100}\right)+2.8+ \\
\left(\frac{1}{V_{s 1}^{*}-\left(K_{a 1} V_{s 1}\right)}-\frac{1}{V_{s 1}^{*}}\right)
\end{array}\right) K_{a 2} \\
& M S D=6.9 \exp \left(\frac{-M_{w}}{4}\right)-0.058
\end{aligned}
$$

Also in Equation 8, a parameter called the corrected $V_{s}$ threshold based on fine content (FC) effect or $V_{s l}{ }^{*}$ is included. The calculation procedure how to estimate $V_{s l}{ }^{*}$ is expressed in these following equations,

$$
\begin{aligned}
V_{s 1}{ }^{*} & =215 \mathrm{~m} / \mathrm{s} \\
V_{s 1}{ }^{*} & =215-0.5(F C-5) \mathrm{m} / \mathrm{s} \\
V_{s 1}{ }^{*} & =200 \mathrm{~m} / \mathrm{s}
\end{aligned}
$$

Equation 10a is used for sandy soils with $\mathrm{FC} \leq 5 \%$, Equation $10 \mathrm{~b}$ is used for sandy soils with $5 \%<\mathrm{FC}<35 \%$ and Equation 10c is used for sandy soils with $\mathrm{FC} \geq 35 \%$.

After CSR and CRR are estimated following the procedure presented above. The factor of safety against liquefaction $(F S)$ can be predicted by using the following equation,

$$
F S=\frac{C R R}{C S R}
$$

Based on Equation 11, the liquefaction potential for a site can be determined. Liquefaction is possible to occur once $F S$ is less than 1 and vice versa.

The procedure in estimating liquefaction presented in Equations 1 to 11 is used for analyzing the sandy soil's depths. However, to quantify the overall vulnerability of liquefaction, a weighting factor method can be implemented. Iwasaki et al. [10] introduced the liquefaction potential index (LPI) to classify liquefaction potential in an area, as expressed in Equation 12,

$$
L P I=\int_{0}^{20} F w(z) d z
$$

In Equation 12, it can be seen that LPI is estimated based on the integration procedure [21]. A parameter called $F$ is related to $F S$. F parameter can be estimated based on these following equations,

$$
\begin{aligned}
& F=1-F S, \text { for } F S \leq 1 \\
& F=0, \text { for } F S>1
\end{aligned}
$$

In addition, a factor related to the depth is also introduced as expressed in this following equation,

$$
w(z)=10-0.5 z
$$

where $z$ is the analyzed depth.

Furthermore, LPI is estimated for each site. Iwasaki et al. [10] mentioned that for engineering practice, liquefaction is generally found up to $20 \mathrm{~m}$ depth; therefore, for calculation of LPI, a maximum depth up to $20 \mathrm{~m}$ depth is considered. For the category of LPI and its classification, Iwasaki et al. [10] mentioned that LPI $=0$ means that there is no liquefaction potential, the criterion of $0<$ LPI $\leq 5$ indicates "low" liquefaction potential, the criterion of $5<$ LPI $\leq 15$ indicates "high" liquefaction potential, and LPI $>15$ indicates "very high" liquefaction potential.

\section{Methodology}

Fig. 3 shows that this study was conducted in Ratu Agung Sub-district, Bengkulu City, Indonesia. This study was initiated by studying the geological conditions as well as soil characteristics. Primary data in the form of shear wave velocity was collected using the Multichannel Analysis of Surface Wave (MASW) method. The measurement location design was made on a grid of 32 observation points with a distance of about 400 meters to represent each geological formation. Furthermore, secondary data was collected in the form of $a_{\max }$ and soil layer conditions from previous studies. The parameters called CSR, CRR, FS, and LPI were calculated using Equations 1 to 13 . Next, soil layer conditions, the liquefied depth, and liquefaction potential, as well as the liquefaction potential category were presented. For detail, Fig. 4 shows the overall framework

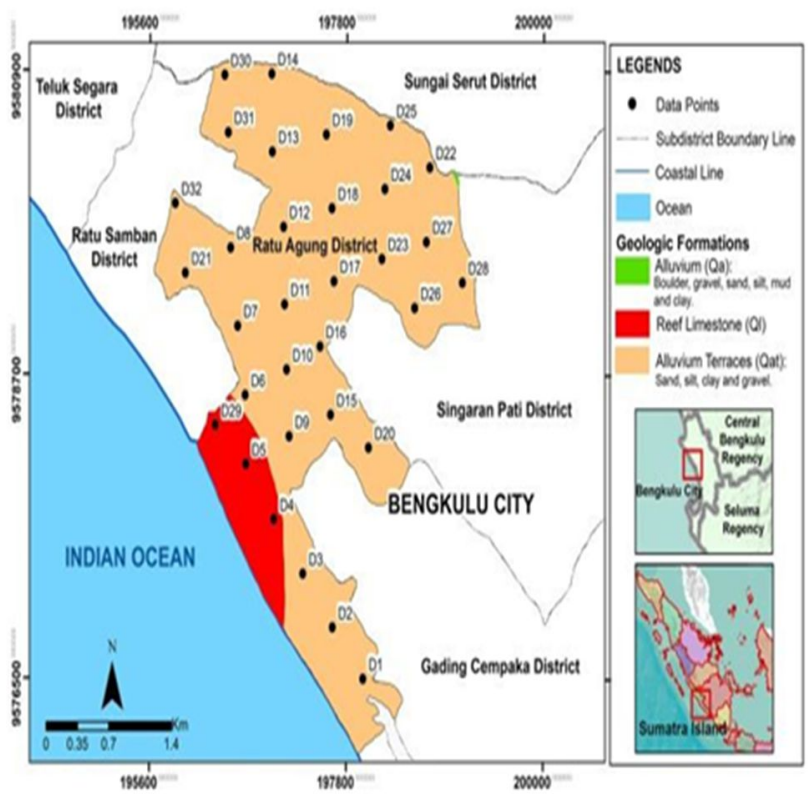

Fig. 3. Study Area, geological formation, and location of site investigation 


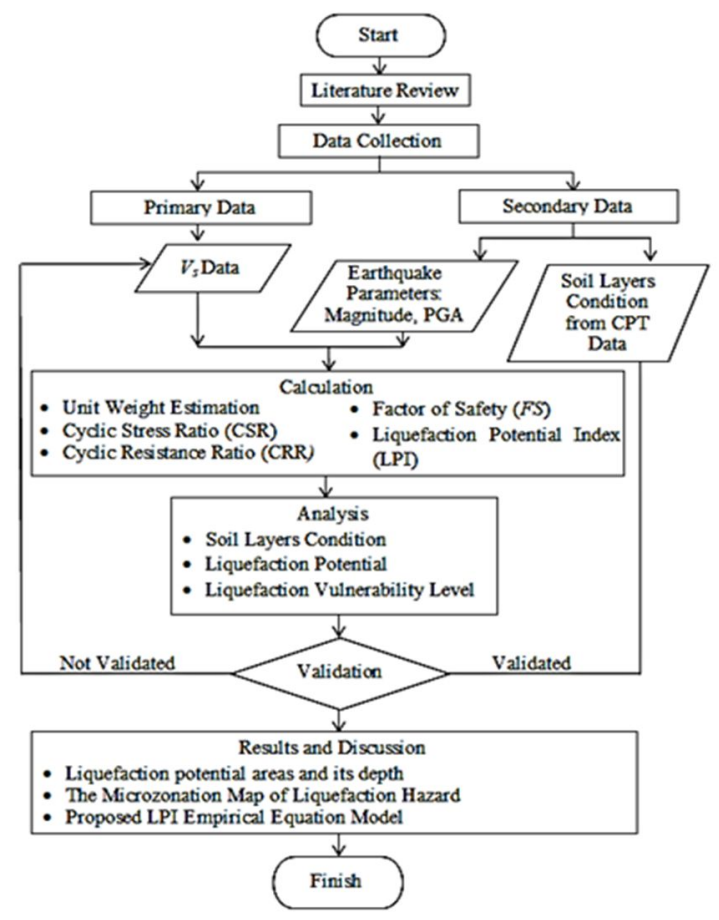

Fig. 4. A research framework for liquefaction potential analysis used in this study

\section{Results and Discussion}

\subsection{Liquefaction Potential}

In this study, the site called Site D2 is used as the representative site to represent the result in the study area. Fig. 5 presents the liquefaction potential of Site D2. It can be observed that liquefaction potentially occurs at the depth of fewer than 7.45 meters. However, the site is generally dominated by sandy soils up to 30 meters in depth. It indicates that the loose sandy soils may be found at the shallow depth, whereas at the deeper depth, the sandy soils with higher soil resistance exist. That prediction is shown by FS more than 1 for those depth ranges. The site is also categorized as Site Class D because $V_{s 30}$ of $330 \mathrm{~m} / \mathrm{s}$ has lied in the range of 180 to 360 $\mathrm{m} / \mathrm{s}$. This study is generally consistent with the study conducted by Mase [22] that mentioned that the coastal area of Bengkulu City is dominated by sandy soils classified as Site Class D.

\subsection{Liquefaction Potential Index (LPI)}

The parameter of $F S$ is obtained from the simplified procedure method. Each soil layer was then measured for its liquefaction potential index to a depth of 20 meters. Fig. 6 presents the LPI map for Ratu Agung District. Fig. 6 also shows that this sub-district has a high liquefaction potential, which is indicated by the yellow zone and the very high zone is indicated by the red color. This may be caused by several factors, such as soil types, maximum acceleration values, and groundwater elevations. Meanwhile, the potential variation is due to the differences in geological conditions in this sub-district.
The LPI values that are estimated from obtained 32 observation points spread across Ratu Agung Sub-district are observed to vary from 5.36 to 29.89 . Those ranges indicate that the liquefaction potential at the site is categorized as high to very high. According to Sugalang \& Buana [7], several areas namely Kebun Beler in D8, Nusa Indah in D6, D9, and D10, Sawah Lebar in D12, as well as Kebun Tebeng Village in D21, D22, D23, D24, and D25 are categorized as the area with high to very high liquefaction potential. This soil type obtained from this study is consistent with the study of Mase [23] that investigated the locations of Lempuing and Pantai Panjang closed to D2 and D27.

The results showed that all test points in the Ratu Agung Sub-district had a high liquefaction potential. This zone is dominated by a soil layer that is very susceptible to liquefaction. This sub-district has cyclical geological processes due to uplift and subsidence by tectonic or past depositional sedimentation.

Furthermore, there is maximum ground acceleration and an increase of earthquake wave vibrations because of the existence of loose sediment. This causes the increase of pore water pressure which later triggers the reduction of soil shear strength. Based on the investigation, past earthquakes that occurred on the $4^{\text {th }}$ of June 2000 and $12^{\text {th }}$ of September 2007 in Ratu Agung Sub-district also cause significant damage, such as lateral spreads, ground settlements, and collapsed buildings
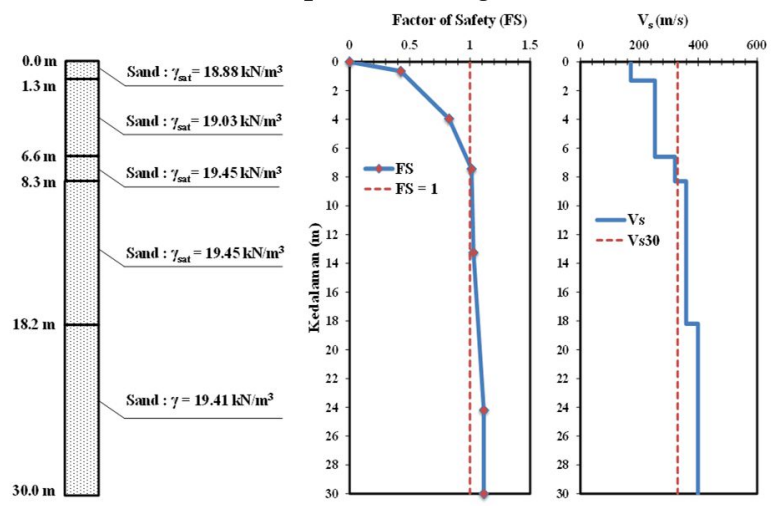

Fig. 5. Soil Layer Condition at Research Point D2

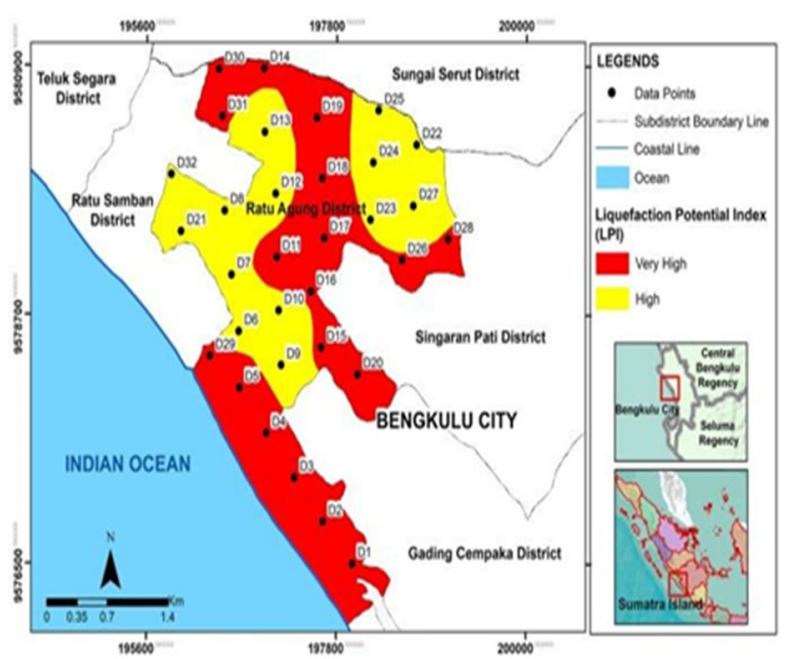

Fig. 6. Liquefaction Hazard Zoning Map in Ratu Agung Subdistrict 


\subsection{Proposed LI Model in Ratu Agung Sub- district}

The LPI value was analyzed to obtain its relationship composed of $V_{s 30}, A_{0}, f_{0}$, and $a_{\max }$. In this study, a multiple linear regression method is conducted to generate an LPI model for Ratu Agung District. Considering the study conducted by Mase [24], $A_{0}$ (amplification factor for the site) and $f_{0}$ (predominant frequency) parameters are known as parameters to define geo-hazard vulnerability. By adopting that previous study, the practical equation for LPI prediction could be generated. The result leads to a proposed equation that depends on internal and external factors. $V_{s 30}, A_{0}, f_{0}$, are categorized as internal factors because they adhered to the soil characteristic, whereas $a_{\max }$ is noted as an external factor. After all, it is related to earthquake energy. The equation to estimate LPI for Ratu Agung District is expressed below,

$$
L P I=0.071 V_{s 30}-1.35 A_{0}-5.74 f_{0}+136.64\left(\frac{a_{\max }}{g}\right) \text { (14) }
$$

Equation 14 obtained from the regression analysis was validated to test the proposed model equation accuracy. The LPI value from Equation 14 is then compared with the calculated one. The result is accurate because it has an $\mathrm{R}^{2}$ value of 0.97 and a Root Mean Square Error (RMSE) of 0.94. Furthermore, the Mean Absolute Percentage Error (MAPE) was $4.64 \%$ in which the value is less than $10 \%$. According to Anggrainingsih et al. [25], a MAPE value less than $10 \%$ indicates a high confidence level of model accuracy. Therefore, the empirical equation proposed in this study is not only considering liquefaction factors but also presents good accuracy and acceptable result. However, it should be noted that the equation is only able to be used for the sites dominated by sandy soils.

In general, the proposed equation is used as initial justification to identify liquefaction and seismic vulnerabilities in Ratu Agung, Bengkulu City, Indonesia. According to Misliniyati et al [26], seismic mitigation studies are important and need to be initiated in coastal zones. In addition, Farid and Mase [27] and Mase [28] showed that these simple improvements could strengthen seismic mitigation efforts in the city.

\section{Conclusion}

This study presents the analysis of liquefaction potential in Ratu Agung District that is identified as one of the impacted areas during strong earthquakes in Bengkulu City, Indonesia. The geophysical measurement is conducted to obtain $V_{s}$ profile that is also used as a soil parameter for liquefaction potential analysis. A mapping of LPI and an empirical equation to predict LPI are also presented in this study. Several concluding remarks can be drawn below,

1. Ratu Agung site is dominated by sandy soils at shallow depth. This sandy soil deposit could be very vulnerable to undergo liquefaction during strong earthquakes.

2. LPI map shows that the yellow and red zones in Ratu Agung Sub-district. It indicates that Ratu Agung District has a high to very high liquefaction potential.
3. The empirical equation proposed in this study could be used for engineering practice for liquefaction potential analysis in Ratu Agung Area.

\section{References}

1. L.Z. Mase, Journal of Engineering \& Technological Sciences 49, 6 (2017)

2. T. Zera, Sutrisno, A. Budiono, IOSR Journal of Applied Geology and Geophysics (IOSR-JAGG) 5 (1) (2017)

3. S. Gafoer, T.C. Amin, R. Pardede, R. Peta Geologi Lembar Bengkulu dan Sekitarnya (Pusat Penelitian dan Pengembangan Geologi Bandung, 1992)

4. M. Farid, A.I. Hadi, Telkomnika 16, 4 (2018)

5. L.Z. Mase, S. Likitlersuang, T. Tobita, Marine Georesources \& Geotechnology 37, 7 (2019)

6. L.Z. Mase, Refrizon, Rosiana, P.W. Anggraini, Indian Geotechnical Journal 51, 8 (2021)

7. Sugalang, T.W. Buana, Buletin Geologi Tata Lingkungan 22, 2 (2012)

8. F. Nugroho, J. Tanjung, M. Zaidir, M. (2018). Observasi Kerusakan Struktur Rangka Beton Bertulang Eksisting Pasca Gempa Palu 2018. In Proceedings of the $5^{\text {th }}$ Andalas Civil Engineering Conference, 28 November 2018, Padang, Indonesia (2018)

9. I.M. Idriss, R.W. Boulanger, Soil liquefaction during earthquakes (Earthquake Engineering Research Institute, Oakland, 2008)

10. T. Iwasaki, K. Tokida, F. Tatsuoka, Soil Liquefaction Potential Evaluation with Use of the Simplified Procedure. In Proceeding of the $1^{\text {st }}$ International Conferences on Recent Advances in Geotechnical Earthquake Engineering and Soil Dynamics, 26 April to 3 May, St Louis, Missouri (1981)

11. L.Z. Mase, S, Likitlersuang, T. Tobita, Journal of Earthquake Engineering (2020) (online)

12. M. Naghizadehrokni, M. Hassanlo, M. Ramzani, International Journal of Geomate, 12, 29 (2017)

13. E. Soebowo, A. Tohari, D. Sarah, K. Sugianti, Procedings of Pemaparan Hasil Pusat Penelitian Geoteknologi LIPI 1 (2014)

14. L.Z. Mase, International Journal of Technology 8, 4 (2017)

15. L.Z. Mase, T.F. Fathani, A.D. Adi, ASEAN Engineering Journal 11, 3 (2021)

16. J.-S. L'Heureux, M. Long, Journal of Geotechnical and Geoenvironmental Engineering 143, 6 (2017)

17. R. Kayen, R.E.S. Moss, E.M. Thompson, R.B. Seed, K.O. Cetin, A.D. Kiureghian, Y. Tanaka, K. Tokimatsu, Journal of Geotechnical and Geoenvironmental Engineering 139, 3 (2013)

18. E.O. Shelley, V. Mussio, M. Rodríguez, J.G.A. Chang, Geofisica Internacional 54, 1 (2015)

19. I.M. Idriss, R.W. Boulanger, Soil dynamics and earthquake engineering 26, 2-4 (2006) 
20. R.D. Andrus, K.H. Stokoe, C.H. Juang, Earthquake Spectra 20, 2 (2004)

21. R.D. Andrus, K.H. Stokoe II, Journal of Geotechnical and Geoenvironmental Engineering (ASCE) 126, 11 (2000)

22. L.Z. Mase, Geotechnical and Geological Engineering 38, 5 (2020)

23. L.Z. Mase, International Journal of Technology 9, 5 (2018)

24. L.Z. Mase, Civil Engineering Dimension 21, 2 (2019)

25. R. Anggrainingsih, G.R. Aprianto, S.W. Sihwi, Time series forecasting using exponential smoothing to predict the number of website visitors of Sebelas Maret University, in Proceedings of the $2^{\text {nd }}$ International Conference on Information Technology, Computer, and Electrical Engineering (ICITACEE), 16 October 2015, Semarang, Indonesia (2015)

26. R. Misliniyati, L.Z. Mase, A.J. Syahbana, E. Soebowo, (2018, December), IOP Conference Series: Earth and Environmental Science 212, 1 (2018)

27. M. Farid, L.Z. Mase, International Journal of Geomate 18, 69 (2020)

28. L.Z. Mase, N. Sugianto, Refrizon. Geoenvironmental Disasters 8, 1 (2021) 